\title{
The effects of letter matrix and inter stimulus interval on P300 Event Related Potential
}

\author{
Nguyen Thi Minh Huong ${ }^{*}$, Vu Nguyen Phuong Quynh
}

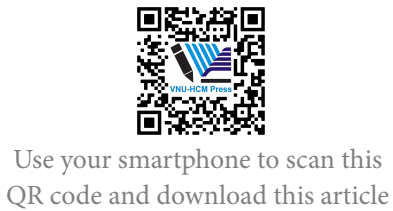

Ho Chi Minh City University of Technology - VNU-HCM, Viet Nam

\section{Correspondence}

Nguyen Thi Minh Huong, Ho Chi Minh City University of Technology VNU-HCM, Viet Nam

Email: nguyentmhuong@ hcmut.com.vn

History

- Received: 09-3-2020

- Accepted: 10-11-2020

- Published: 15-1-2021

DOI : 10.32508/stdjet.v3iSI3.681

\section{Check for updates}

Copyright

(c) VNU-HCM Press. This is an openaccess article distributed under the terms of the Creative Commons Attribution 4.0 International license.

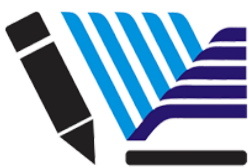

VNU-HCM Press

ABSTRACT

In the recent years, there are many people suffering from the loss of all voluntary muscle control in Viet Nam (Thanh, 2019). Therefore, they really need alternative interaction methods to control their behaviours with external environment. Many researches have been rapidly increased on this topic. Thanks to the development of Brain-Computer interfaces and the EEG headset have been helping people who are incapable of any motion for function can communicate with the external world. There are some features which have been considered as inputs in $\mathrm{BCl}$ system. We choose P300 signal to link $\mathrm{BCl}$ operation due to on its own advantages by some previous researches (Birbaumer and et al., 1999, Eric and et al., 2006). As the important consideration to discover which factors affect the accuracy of $\mathrm{BCl}$ system to improve communication quanlity for the ability of disabled people, we decide to discover the impact of character matrix size and inter stimulus interval on event related potential - P300 signal. The duration of the inter stimulus interval (ISI) between targets is set at $187,5 \mathrm{~ms}$ and $125 \mathrm{~ms}$ for two different matrix size $3 \times 3$ and $6 \times 6$. These experiments were done by five people ( 4 man and 1 woman age from 21 to 22) with helping of Emotiv Epoc. The results provide that the largest amplitudes of P300 waveforms occur remarkably at the occipital and frontal channels and are higher than in $6 \times 6$ letter matrix compared with $3 \times 3$ matrix. The different matrix size and ISI does not affect on the appearance time of the P300 signal, and it is in the range 235-244 ms after stimulation. These good results promise to help other researches to build an perfect experimental procedure in real assistance application for using $\mathrm{BCl}-\mathrm{P} 300$ systems.

Key words: $\mathrm{EEG}, \mathrm{BCl}, \mathrm{P} 300, \mathrm{ISI}, \mathrm{EPOC}$

\section{INTRODUCTION}

Taccording to the General Statistics Office (Ministry of Planning and investment) collaborated with the United Nations Children's Fund in Viet Nam, from 2016 to 2017, there were nearly 5 million households which had disabilities in the country. The proportion of people with disability who were over 2 years old accounted for $7 \%$ of the population ${ }^{1}$. Another statistic is based on the Christopher \& Dana Reeve Foundation report in 2013, about 5.4 million Americans suffer from disability ${ }^{2}$. Many research works therefore have been built with the aim of improving the ability of movement and communication, based on biomedical signals, especially Brain Computer Interface (BCI) system. BCI is technology that enables the use of the brain's neural activity to communicate with others or to control machines, artificial limbs, or robots without direct physical movements. BCI based on electroencephalogram (EEG) can be applied to disabled individuals system. There are some different features considered as inputs of BCI such as some brain waves (e.g., mu or beta rhythms) ${ }^{3}$, and slow cortical potentials $^{4}$ and event-related potentials (ERP) ${ }^{3}$. Hav- ing said that BCI - ERP reach high accuracy in online communication given in many researches ${ }^{5}$. Morever, BCI using P300 input had acceptable accuracy in helping patients with amyotrophic lateral sclerosis $4,6,7$. However, there are few articles discussed about factors in odd ball paradigm makes effects on P300 signals in BCI. In the paper ${ }^{8}$ gave important result that increasing the dimensions (i.e., the numbers of rows and columns) of the matrix, while holding the size of the matrix elements constant, resulted in larger P300. The lastest paper ${ }^{7}$ made significant contributions in reviewing the effects of matrix size and inter stimulus interval on performance. This paper concluded that accuracy was higher in the $175-\mathrm{ms}$ ISI condition than in the 350-ms ISI condition. It solved some our questions and also brings benefits in designing our experiments. In the first steps, our group had relative positive results in acquisition $\mathrm{P} 300$ waveform and classification P300 for letter matrix size $2 \times 2,3 \times 3$ and $6 \times 6$ and inter stimulus interval $200 \mathrm{~ms}^{8}$. Matrix $2 \times 2$ symbolises four actions upward, downward, rightward and leftward in realistic model our group has been desired to implement. Matrix 3x3 contains 
suitable number of letters and words in realistic controlling model. Besides, it is a reasonable choice for classification by high accuracy. While matrix $6 \times 6$ is a basic option in most of experiments aiming to detect $\mathrm{P} 300$ waveform. This is because the probability of the target being flashed was 0.17 , and such improbable events had been shown to produce robust $\mathrm{P} 300 \mathrm{~s}^{9}$. For main reasons, our group does experiments in conditions of 2 matrixes $3 \times 3$ and $6 \times 6$ and the duration of the inter stimulus interval (ISI) between targets is set at $187,5 \mathrm{~ms}$ and $125 \mathrm{~ms}$ to examine appearance time of P300 and its amplitude to optimise experiemental system and algorithm in BCI. During the experiments, our group used EMOTIV EPOC contains 14 Electroencephalogram (EEG) channels and the sampling rate at $128 \mathrm{~Hz}$ to collect EEG signals of vonlunteers. This device is benificial for flexibility and accurate enough for measuring EEG signals.

This paper is organized as follows. In section 2, we describe the algorithms for filtering, estimating amplitudes and appearance time of P300 signals. In section 3, the P300 signals are shown and compared about amplitude and time of its appearance for two matrix size $3 \times 3$ and $6 \times 6$ and two ISIs $125 \mathrm{~ms}$ and $187.5 \mathrm{~ms}$ respectively. Some discussions are shown in section 4 and conclusions are provided in Section 5.

\section{METHOD}

To conduct this study, we recoded the raw EEGs from the uers scalp through the EPOC. Then the data was preproccessed before we epoch the EEG data and performed the band pass filtering on it $(1-20 \mathrm{~Hz})$ by EEGLAB. Then the $\mathrm{P} 300$ detection was proceeded. Finally, we discussed the results in term of advantages and disadvantages as well as related problems.

\section{Experimental Procedure and EEG data}

Five people (4 man and 1 woman age from 21 to 22 ) participated in this study. All of them had no history of neuropathy, healthy and have not had previous BCI experiences. The experiment was designed and run in the basement of the BCI 2000 sofware and Odd-ball paradigm in conditions of 2 matrixes $3 \times 3$ and $6 \times 6$ and the duration of the inter stimulus interval (ISI) between targets is set at $187,5 \mathrm{~ms}$ and $125 \mathrm{~ms}$ as following tables. The volunteer was asked to pay his (her) attention to the letter serves target in oddball paradigm in below conditions our group set up and it elicits P300 response. Table 1 shows the parameters in odd ball paradigm with ISI duration $125 \mathrm{~ms}$ of both matrix $3 \times 3$ and $6 \times 6$. As we can see, there are 60 flasing times in one trial and 20 flasing times of target in one trial for matrix $3 \times 3$ and 10 others for matrix
$6 x 6$. It means because the probability of the target being flashed was 0.33 and 0,17 for matrix $3 \times 3$ and $6 \times 6$ accordingly.

Table 1: Experimental paramaters with 125 ms stimulus duration.

\begin{tabular}{ll}
\hline Sequencing & Parameters \\
Flasing times in one trial & 60 \\
Number of selected characters & 14 \\
Stimulus Duration & $125 \mathrm{~ms}$ \\
ISIMin Duration & $125 \mathrm{~ms}$ \\
$\begin{array}{l}\text { Temporal latency between con- } \\
\text { secutive characters }\end{array}$ & $1.25 \mathrm{~s}$ \\
$\begin{array}{l}\text { Flashing times of target in one } \\
\text { trial }\end{array}$ & $20(3 \times 3) ; 10(6 \times 6)$ \\
\hline
\end{tabular}

Table 2 shows the parameters are same others in Table 1 except for ISI $187.5 \mathrm{~ms}$. The speed of the highlighting determines the number of characters processed per minute is 2,6 characters/minute.

Table 2: Experimental paramaterswith 187.5 ms stimulus duration

\begin{tabular}{ll}
\hline Sequencing & Parameters \\
Flasing times in one trial & 60 \\
Number of selected characters & 14 \\
Stimulus Duration & $125 \mathrm{~ms}$ \\
ISIMin Duration & $187.5 \mathrm{~ms}$ \\
$\begin{array}{l}\text { Temporal latency between consec- } \\
\text { utive characters }\end{array}$ & $1.25 \mathrm{~s}$ \\
Flashing times of target in one trial & $20(3 \times 3) ; 10(6 \times 6)$ \\
\hline
\end{tabular}

The experimental procedures include 6 steps, which will be concretely listed in this part:

- Step 1: Volunteers sat comfortably in front of a 17 - inch computer screen at a distance of 30 to $40 \mathrm{~cm}$.

- Step 2: Let the volunteers relax for 1 to $2 \mathrm{~min}-$ utes.

- Step 3: Explained the procedure and process of the experiments to the volunteers.

- Steps 4: Required the volunteers to wear the EMOTIV EPOC device and check the battery and the quality of the signal recorded by electrodes.

- Step 5: Checked the feeling of the volunteers when they wore the headset.

- Step 6: Recorded the raw data. 


\section{Data Analysis Method}

\section{Preprocessing}

Frequencies of EEG signals are less than $100 \mathrm{~Hz}$. In addition, most recordings present a $50-\mathrm{Hz}$ frequency component contaminating several electrodes. Therefore, the signals need to be lowpass filtered to eliminate this frequency component and other highfrequency components generally produced by muscular activity. A Butterworth filter of order 10 with a cutoff frequency of $20 \mathrm{~Hz}$ is used ${ }^{10}$. Within this range of frequencies, we still have the complete information about the P300 signals. The Butterworth filter is one of the signal processing filter, which is designed to have a frequency response as flat as possible. It was first introduced in 1930 by the British engineer and physist Stephen Butterworth in his paper "On the Theory of Filter Amplifiers" The amplitude G of the feedback signal having frequency w output of the filter is calculated by the formula:

$$
|G(w)|^{2}=\frac{1}{1+\left(\frac{w}{w_{c}}\right)^{2 N}}
$$

$\mathrm{N}$ is the number of poles in the filter. $\mathrm{w}_{c}$ is the cutoff frequency $(\mathrm{rad} / \mathrm{s})$.

\section{Obtain P300 signal}

ERP signals can be collected from EEG signal, this is the process of measure the temporal active potential of the brain using electrodes attached to the scalp. The recorded EEG signal is the results of many simultaneous processes in the brain, which means the brain's response to a single stimulus or event cannot be recognised. In order to see how the brain responded to the stimuli, it is imperative that the experiment had many stimuli and tests. The average result of several attempts is then calculated and the resulting waveform is the event related potential (ERP) ${ }^{9}$.

The recorded ERP signal includes not only necessary signal in data visualization process but also may kinds of artifacts: EMG, EOG, electrical grid...ERP signal potential (P300) is extracted from the following formula: ${ }^{5,6}$

$$
\begin{aligned}
\bar{x}(t) & =\frac{1}{N} \sum_{k=1}^{N} x(t, k) \\
& =s(t)+\frac{1}{N} \sum_{k=1}^{N} n(t, k)
\end{aligned}
$$

With:

$\mathrm{N}$ : total number of stimuli

$\mathrm{k}$ : $\mathrm{kth}$ stimulus in $\mathrm{N}$ ( $\mathrm{k}$ from 1 to $\mathrm{N}$ )

t: time elapsed after the kth stimulus

$s(t)$ : ERP signal function

$\mathrm{n}(\mathrm{t}, \mathrm{k})$ : noise signal fuction

\section{RESULTS}

Signals are firstly preprocessed by Butterworth filter of order 10 with a cutoff frequency of $20 \mathrm{~Hz}$ to remove noise $50 \mathrm{~Hz}$ and high-frequency components. After import the filted data and the event file with 140 stimuli into EEGLAB, we continue to update the location file, select the Epoch interval from -1 to 2 and perform baseline elimination. Before plotting the P300 signal, basic noise filtering steps are taken to eliminate unnecessary signals such as grid, blink, etc.

\section{$3 \times 3$ speller matrix with 125 ms stimulus du- ration}

Figure 1 shows P300 waveform of one volunteer perform in experiment with matrix $3 \times 3$ and ISI $125 \mathrm{~ms}$. After the noise filter is completed, it becomes easier to check the appearance of the desired P300 signal by plotting a multi-channel graph, the recording information including wave shape, time of P300.

The P300 signal has appeared in many channels such as AF3, F7, T8, AF4 but the it is clear and nearly identical to the most standard signal appearing in the P7 and P8 channels. This is true for a number of studies that have been done, 4 channels $\mathrm{P} 7, \mathrm{P} 8, \mathrm{O} 1, \mathrm{O} 2$ are considered the most obvious places where P300 exists $^{11,12}$. Specifically at the P7 channel position, the P300 signal appears $251.2 \mathrm{~ms}$ after stimulation and has a amplitude of $4.76 \mu \mathrm{V}$. In the P8 channel, the signal is $5.022 \mathrm{~V}$ and appears $201.5 \mathrm{~ms}$ after stimulation.

\section{$3 \times 3$ speller matrix with 187.5 ms stimulus duration}

It can be seen in Figure 2 that the P300 signals appear clearly on channels P7, P8 and F8. At the channel position of P7, the peak amplitude of the signal reaches $6.85 \mu \mathrm{V}$ at $167.5 \mathrm{~ms}$ after excitation. Meanwhile at channel P8, signal P300 appears at $236.7 \mathrm{~ms}$ after excitation and peaked amplitude is $6.12 \mu \mathrm{V}$.

\section{6x6 speller matrix with 125 ms stimulus du-} ration

As we can see in Figure 3, P300 signals appear clearly on channels P7, P8 and O1. The peak amplitudes at channels $\mathrm{P} 7$ and $\mathrm{P} 8$ are $5.21 \mu \mathrm{V}$ and $6.41 \mu \mathrm{V}$, respectively. The time of appearance of P300 signal at channel P7 is $228.8 \mathrm{~ms}$ after stimulation while that of channel P8 is $236.7 \mathrm{~ms}$.

6x6 speller matrix with 187.5 ms stimulus duration

The Figure 4 shows that P300 signals appear clearly in two channels P7 and P8 with peak amplitudes of 9.77 

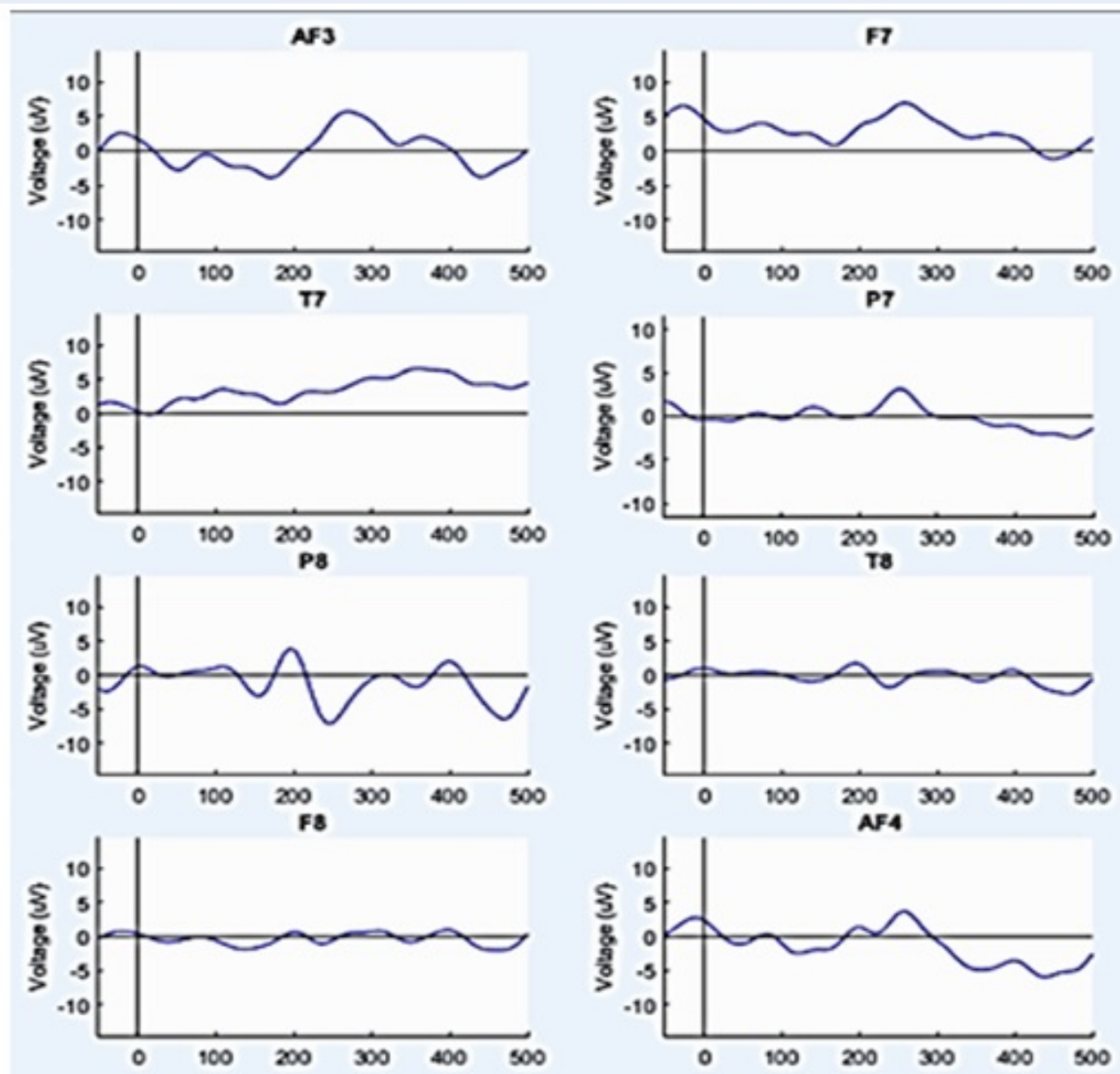

Figure 1: ERP signal of $3 \times 3$ matrix experiment ploted in multi-channel(125ms).

$\mu \mathrm{V}$ and $9.68 \mu \mathrm{V}$, respectively. The time of appearing $\mathrm{P} 300$ signal at P7 is $250.3 \mathrm{~ms}$ and channel P8 is 247.8 ms.

\section{DISCUSSIONS}

Some main results can be discussed here. Firstly, the P300 waveform appeears with largest amplitude at the occipital and frontal areas such as P7, P8, O1, O2. Secondly, time of appearance of P300 waveform is about $240 \mathrm{~ms}$. These results are in agreement with published articles such as of Escolano, Antelis and Minguez ${ }^{13}$.

Finally, in order to compare amplitudes and time P300 survives, our group plots average amplitude and time of P300 of 4 channels P7, P8, O1, O2 for two types of matrix size $3 \times 3$ and $6 \times 6$ and two ISI $125 \mathrm{~ms}$ and 187.5 ms accordingly.

Figure 5 describes average amplitudes of two channels P7 and P8 for ten volunteers of matrix $3 \times 3$. As we can see, average amplitudes of P300 signals for ISI 187,5 ms are higher than others of ISI $125 \mathrm{~ms}$ for all volunteers. Average amplitude for ISI $125 \mathrm{~ms}$ is about $4 \mu \mathrm{V}$ and $7 \mu \mathrm{V}$ for ISI $187.5 \mathrm{~ms}$.

Figure 6 illustrates average time of two channels P7 and P8 for ten volunteers of matrix $3 \times 3$. A more detailed look at the figure reveal that values of appearance time of P300 signals are the same for ten volunteers. These values is about $240 \mathrm{~ms}$ which is suit to theory of P300 signals ${ }^{13}$.

Figure 7 is graphic of average amplitudes of two channels P7 and P8 for ten volunteers of matrix $6 \times 6$. Both of them show steadily trends for all of volunteers. The former has average value is at about $7 \mu \mathrm{V}$, the later is about $10 \mu \mathrm{V}$.

Figure 8 illustrates average time of two channels P7 and P8 for ten volunteers of matrix $6 \times 6$. The values of appearance time of P300 signals are the same for ten volunteers. These values is about $240 \mathrm{~ms}$ is suit to theory of P300 signals ${ }^{14}$. 

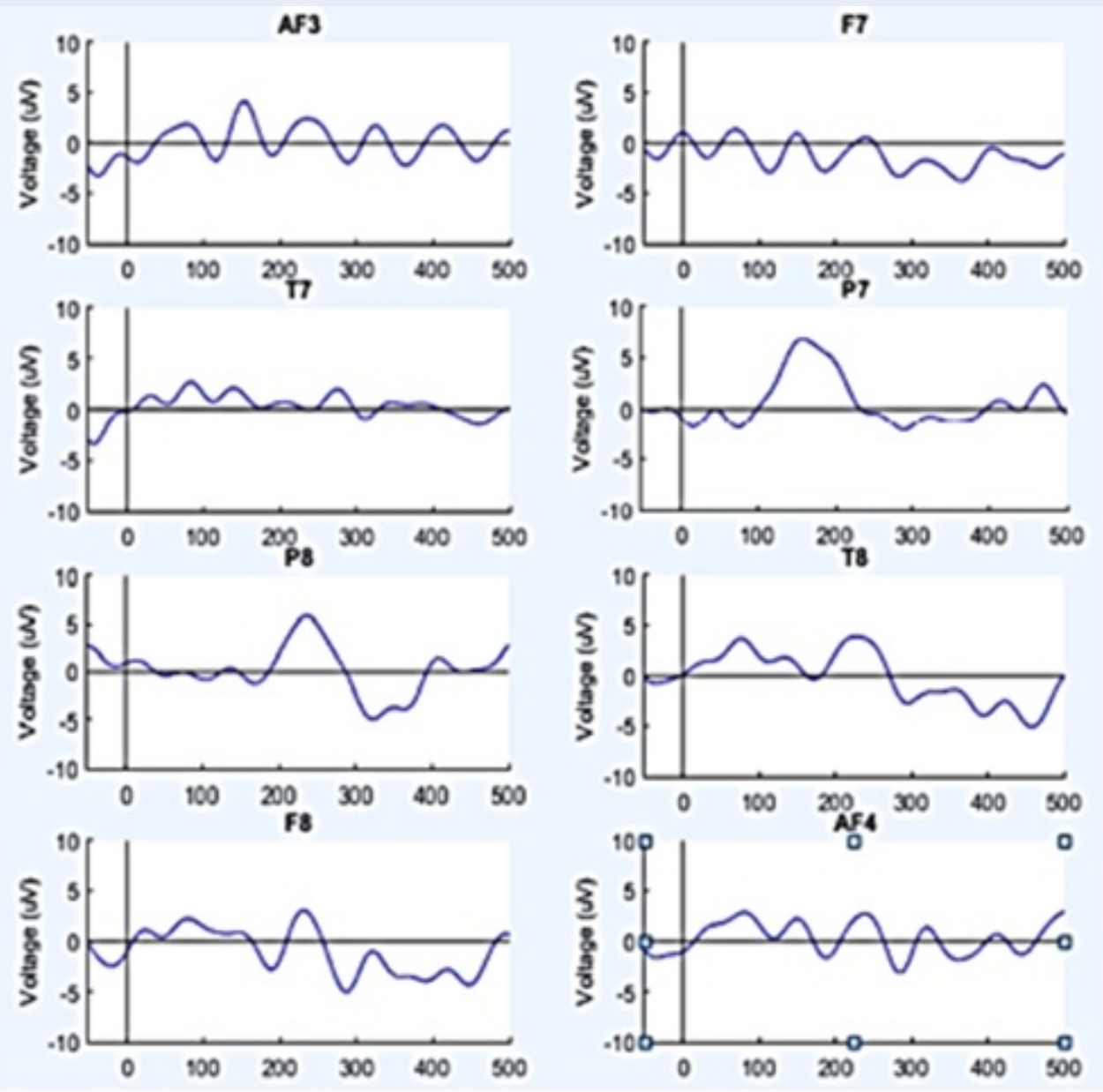

Figure 2: ERP signal of $3 \times 3$ matrix experiment ploted in multi-channel(187.5ms).

For the most general comparisions purposes, our group desribes mean values of amplitude and time of P300 signals of ten volunteers for two matrix $3 \times 3$ and 6x6 with ISI $125 \mathrm{~ms}$ and $187.5 \mathrm{~ms}$ as Tables 3 and 4. To conclude that, changing the matrix size does not affect the time of the P300 signal (specifically, the time of appearing in the range 235-244 ms after stimulation), however it affects the amplitude of the P300 signal. Specifically, the amplitude of the signal P300 of matrix $6 \times 6$ will be larger than the matrix of $3 \times 3$. This result is similar to some studies that have been done ${ }^{15,16}$. In general, the amplitude of the P300 wave will increase as we increase the stimulus duration in both types of matrices. This is considered reasonable when compared to previous research, the longer the stimulation time, the greater the amplitude of $\mathrm{P} 300^{15}$.

\section{CONCLUSIONS}

By understanding how the letter matrix size and inter stimulus interval have an impact on the quality of the evoked responses. Our further researches will base on matrix size $3 \times 3$ and ISI $187.5 \mathrm{~ms}$ to complete experimental procedure in contronlling external device by EEG signals.

\section{ACKNOWLEDGEMENT}

This research is funded by Vietnam National University HoChiMinh City (VNU-HCM) under grant number C2020-20-11.

\section{LIST OF ABBREVIATIONS}

EEG: Electroencephalogram.

BCI: Brain Computer Interface

ERP: Event Related Potentials

ISI: Inter Stimulus Interval 

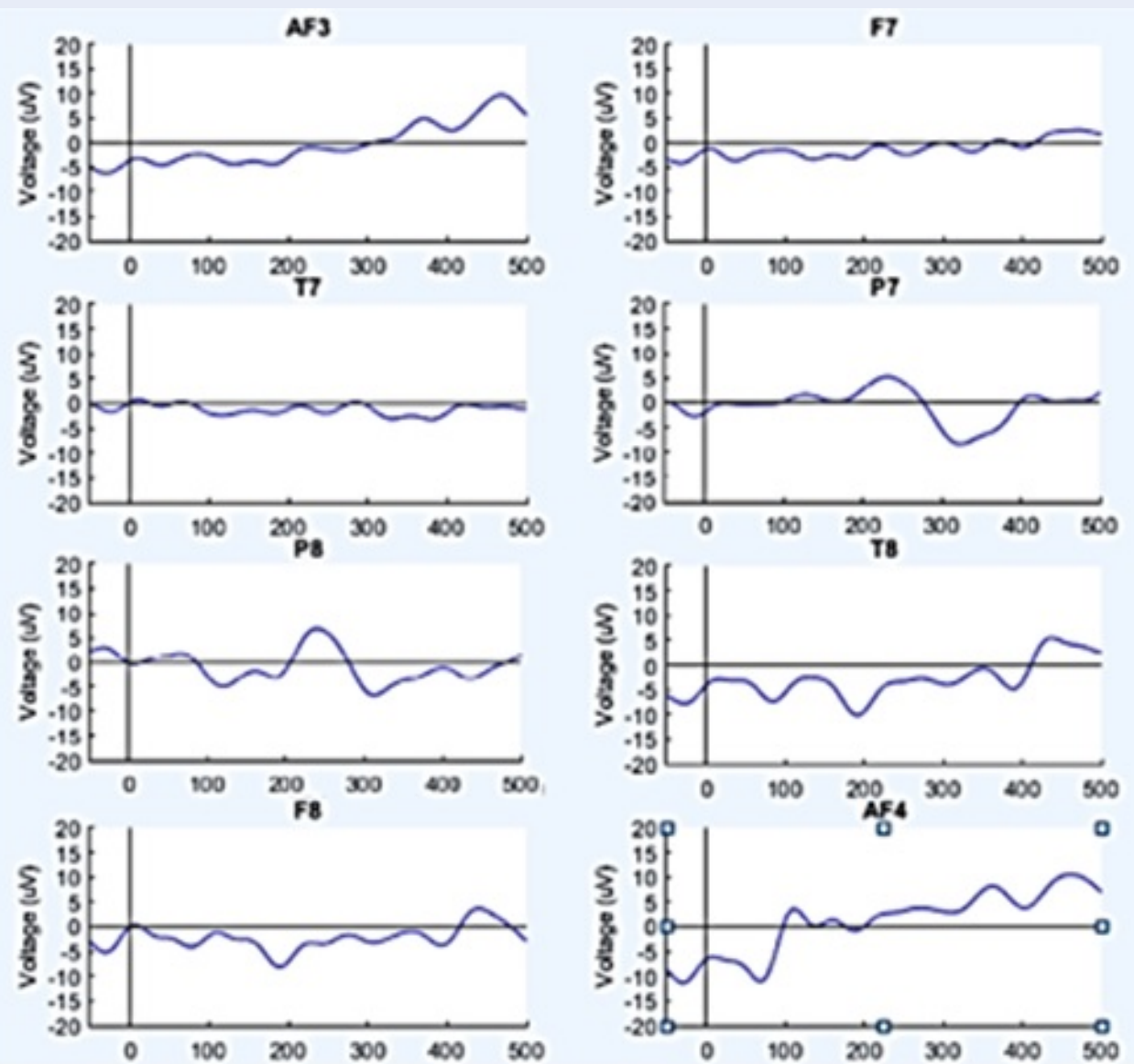

Figure 3: ERP signal of $6 \times 6$ matrix experiment ploted in multi-channel(125ms)

Table 3: Mean value of p300 signal amplitude $(\mu v)$ in two channels $p 7$ and p8 of both $3 \times 3$ and $6 \times 6$ matrix experiments.

\begin{tabular}{lllll}
\hline $\begin{array}{l}\text { Stimulus } \\
\text { Duration }\end{array}$ & $\begin{array}{l}\text { Time of appearance of P300 signal in } \\
\text { channel P7(ms) }\end{array}$ & $\begin{array}{l}\text { Time of appearance of P300 signal in chan- } \\
\text { nel P8(ms) }\end{array}$ \\
& $3 \times 3$ & $6 \times 6$ & $3 \times 3$ & $6 \times 6$ \\
$125 \mathrm{~ms}$ & 240.5 & 241.3 & 236.5 & 241.9 \\
$187.5 \mathrm{~ms}$ & 235.8 & 242.2 & 238.75 & 243.8 \\
\hline
\end{tabular}

Table 4: Mean value of time of appearance in two channels p7 and p8 of both $3 \times 3$ and $5 \times 6$ matrix experiments.

\begin{tabular}{llcll}
\hline Stimulus Duration & $\begin{array}{l}\text { Amplitude of P300 signal in channel P7 } \\
(\mu \mathbf{V})\end{array}$ & $\begin{array}{l}\text { Amplitude of P300 signal in channel P8 } \\
(\mu \mathbf{V})\end{array}$ \\
& $3 \times 3$ & $6 \times 6$ & $3 \times 3$ & $6 \times 6$ \\
$125 \mathrm{~ms}$ & 3.71 & 6.23 & 3.98 & 5.99 \\
$187.5 \mathrm{~ms}$ & 6.98 & 9.47 & 6.93 & 10.55 \\
\hline
\end{tabular}


AF3
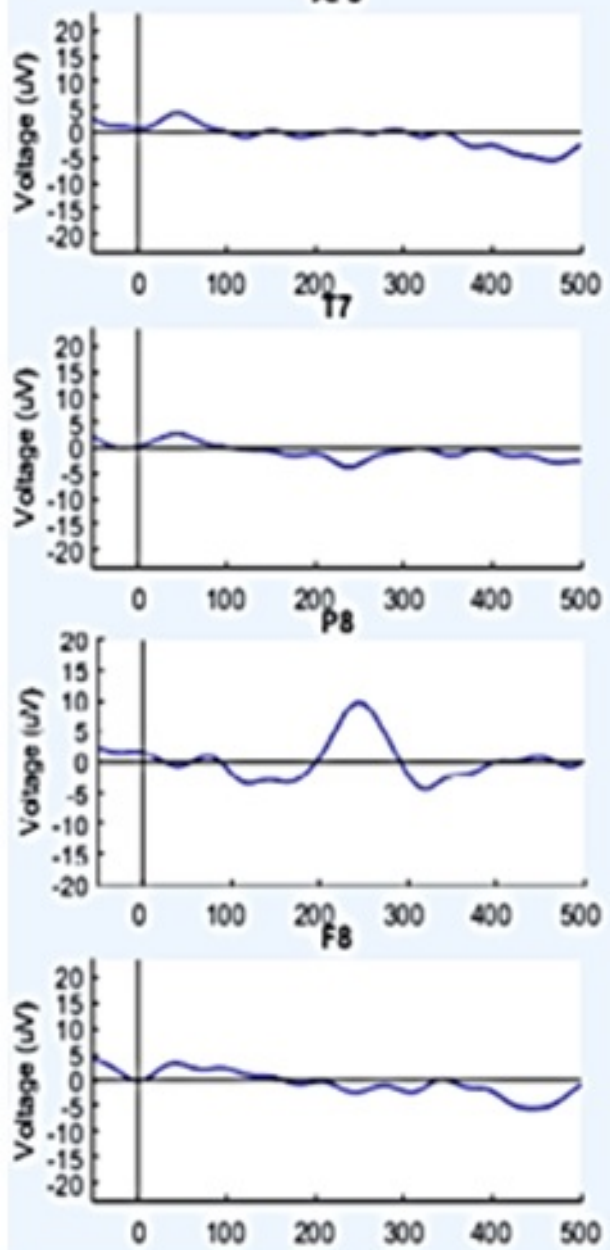

F7
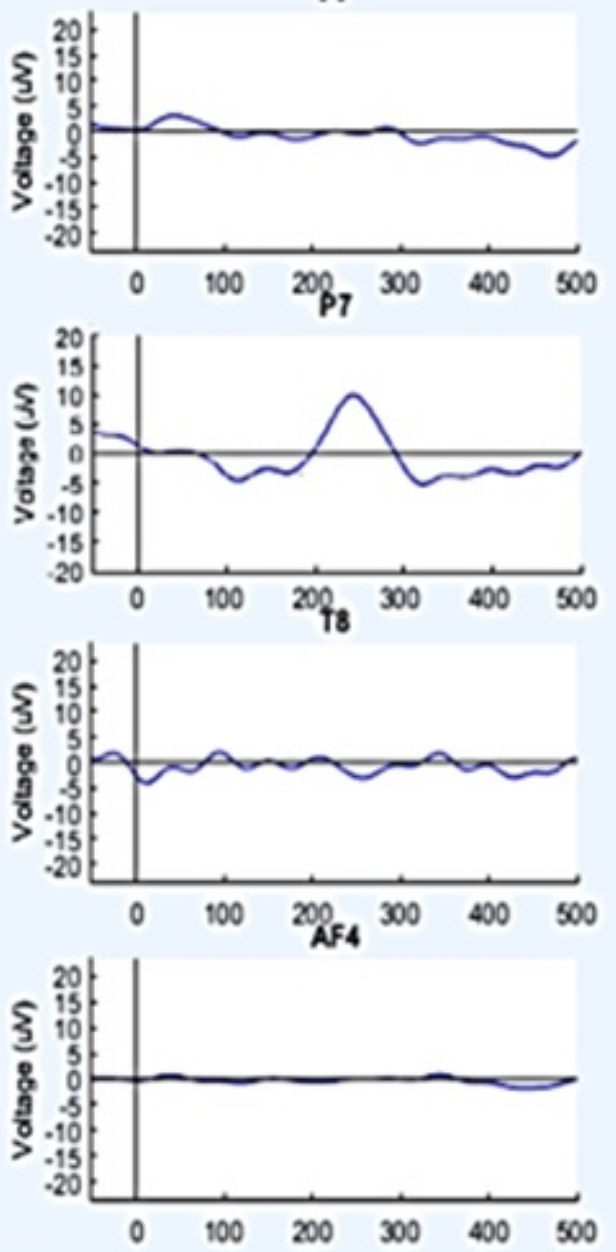

Figure 4: ERP signal of $6 \times 6$ matrix experiment ploted in multi-channel(187.5ms)

\section{AUTHOR CONTRIBUTIONS}

All authors contributed equally to this work. All authors have read and agreed to the published version of the manuscript.

\section{CONFLICT OF INTEREST}

We declare that there is no conflict of whatsoever involved in publishing this research.

\section{REFERENCES}

1. Thanh K. VOVVN [Accessed 153 2019]. Đài tiếng nói Việt Nam. 2019;Available from: https://vov.vn/xa-hoi/tang-soluong-nguoi-khuyet-tat-trong-tuong-lai-863204.vov.

2. Christopher DR. Christopher \& Dana Reeve Foundation [ACcessed 153 2019]. Christopher \& Dana Reeve Foundation. 2013;Available from: https://www.christopherreeve.org/livingwith-paralysis/stats-about-paralysis.

3. Rivet B, Souloumiac A, Attina V, Gibert G. xDAWN algorithm to enhance evoked potentials: application to brain-computer interface. IEEE Trans Bio-med Eng. 2009;56(8):2035-2043. Avail- able from: https://doi.org/10.1109/TBME.2009.2012869.

4. Birbaumer N, et al. A spelling device for the paralyzed. Nature. 1999;398:297-298. PMID: 10192330. Available from: https: //doi.org/10.1038/18581.

5. Sellers EW, et al. A P300 event-related potential braincomputer interface $(\mathrm{BCl})$ : The effects of matrix size and inter stimulus interval on performance. Biological Psychology. 2006;73:242-252. PMID: 16860920. Available from: https: //doi.org/10.1016/j.biopsycho.2006.04.007.

6. bler AK, et al. Patients with ALS can learn to operate a sensorimotorrhythm based brain-computer interface (BCI). Neurology. 2005;64:1775-1777. PMID: 15911809. Available from: https://doi.org/10.1212/01.WNL.0000158616.43002.6D.

7. Sellers EW, Donchin E. A P300-based brain-computer interface: Initial tests by ALS patients. Clinical Neurophysiology. 2006;117:538-548. PMID: 16461003. Available from: https: //doi.org/10.1016/j.clinph.2005.06.027.

8. Huong NTM, Nguyen NT, Linh HQ. The characteristics of the event-related potentials with visual stimulus, 7th International Conference on the Development of Biomedical Engineering in Vietnam (BME7). IFMBE Proceedings. 2008;69:513520.

9. Allison BZ, Pineda JA. ERPs evoked by different matrix sizes: Implications for a brain computer interface $(\mathrm{BCl})$ systemngi- 


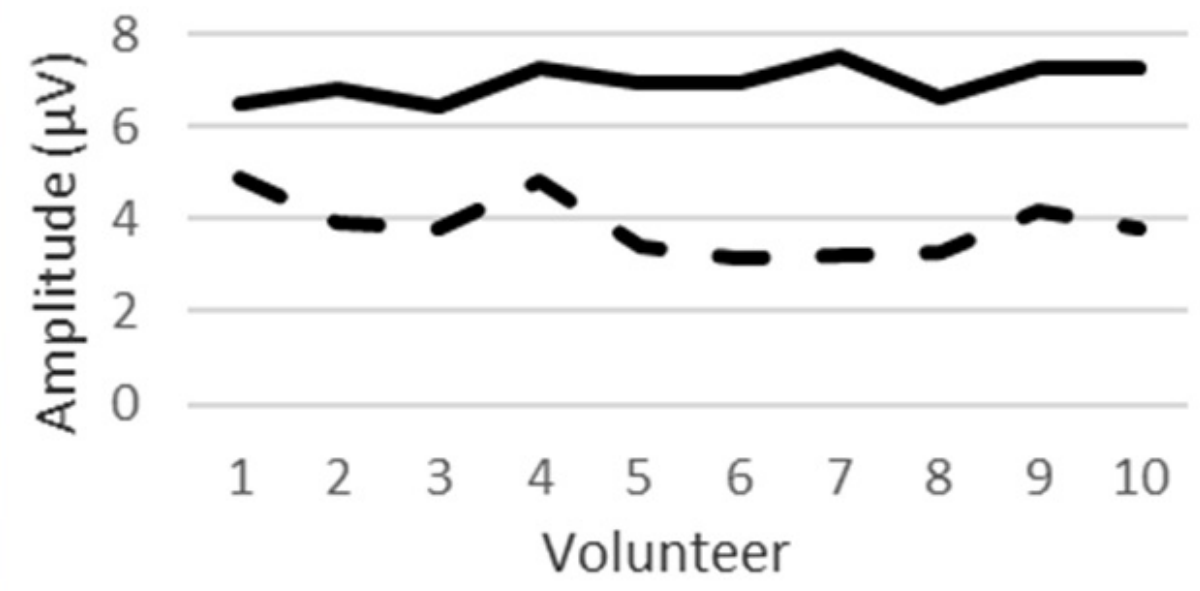

- $125 \mathrm{~ms} \longrightarrow \mathrm{ms}$

Figure 5: Average amplitudes of two channels P7 and P8 for ten volunteers of matrix $3 \times 3$.

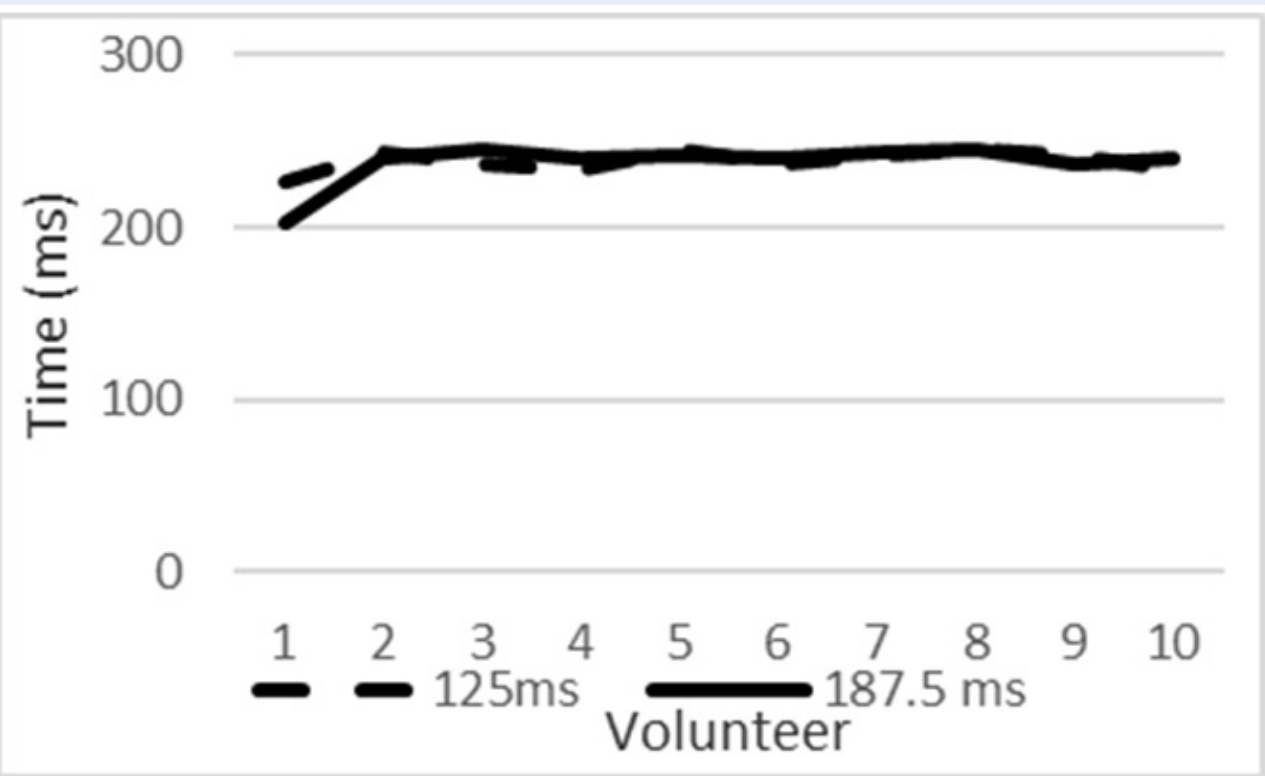

Figure 6: Average time of two channels P7 and P8 for ten volunteers of matrix $3 \times 3$. 


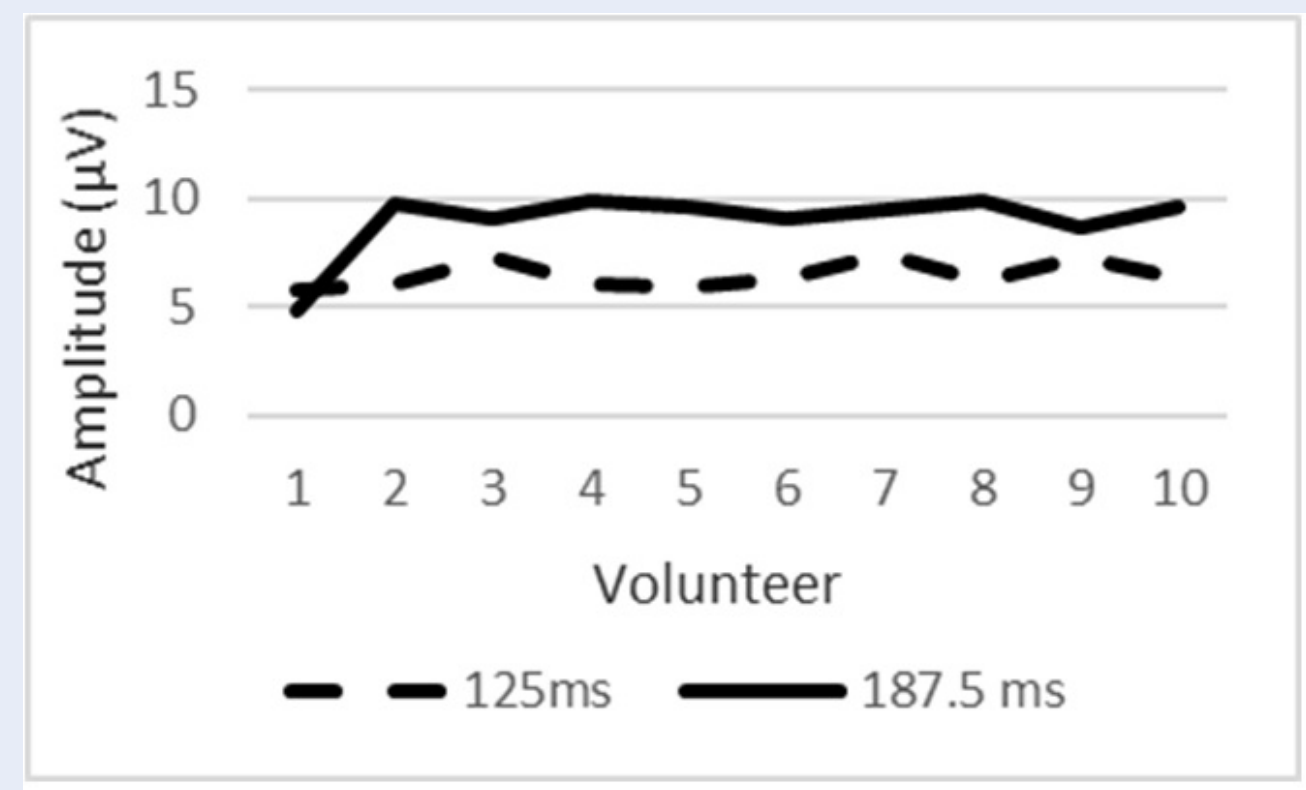

Figure 7: Average amplitudes of two channels P7 and P8 for ten volunteers of matrix $6 \times 6$.

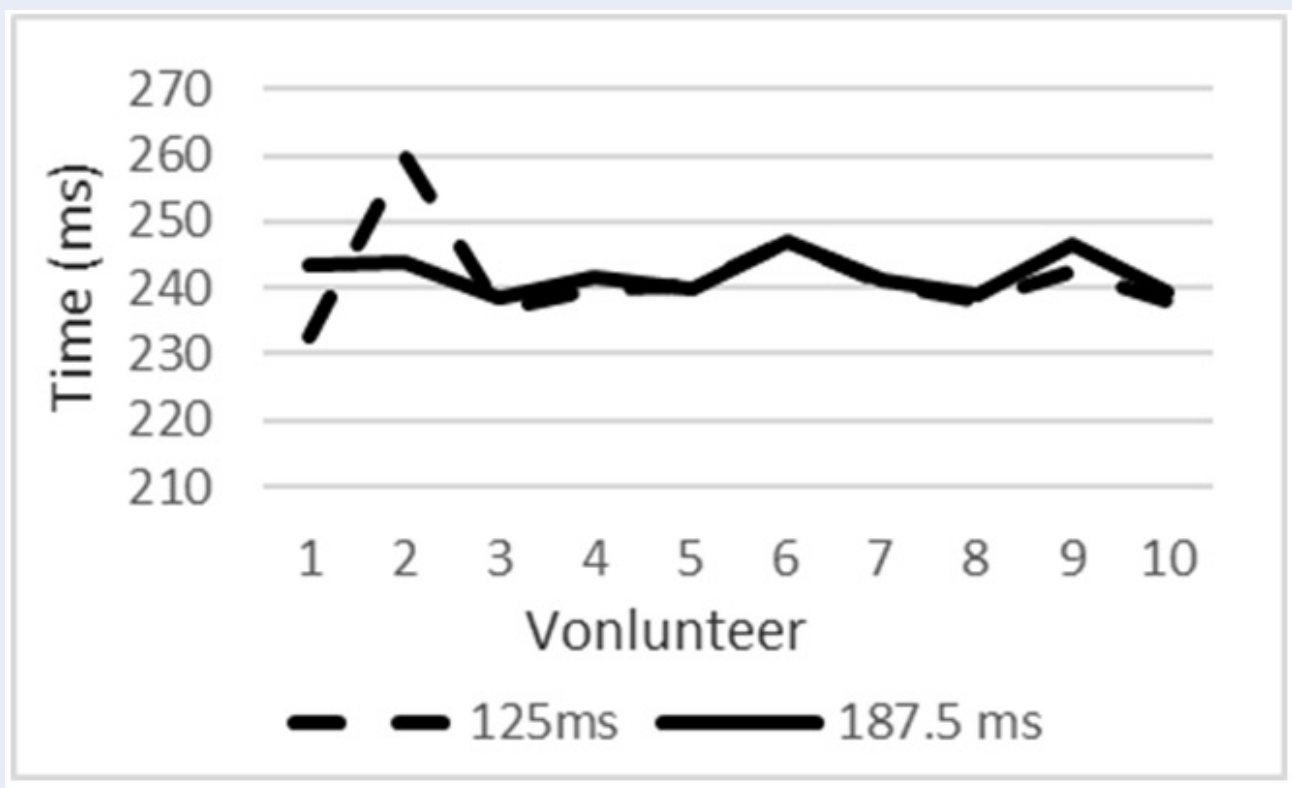

Figure 8: Average time of two channels P7 and P8 for ten volunteers of matrix $6 \times 6$. 
neering 11, 110-113, 2003. . IEEE Transactions on Neural Systems and Rehabilitation E;PMID: 12899248. Available from: https://doi.org/10.1109/TNSRE.2003.814448.

10. Butterworth S. Theory of filter amplifiers. Experimental wireless \& the wireless engineer. 1930;7:536-541.

11. Colwell KA. Channel Selection Methods for the P300 Speller. J Neurosci Methods. 2014;232:6-15. PMID: 24797224. Available from: https://doi.org/10.1016/j.jneumeth.2014.04.009.

12. Pontifex MB. Age, physical fitness, and attention: P3a and P3b. Psychophysiology. 2009;46(2):379-387. PMID: 19170947. Available from: https://doi.org/10.1111/j.14698986.2008.00782.x.

13. Escolano C, Antelis J, Minguez J. Human Brain-Tekeioerated Robot between Remote Places. IEEE International Conference on Robotics and Au-tomationp, Kobe, Japan. 2009;p. 44304437. Available from: https://doi.org/10.1109/ROBOT.2009. 5152639.

14. Sellers EW. A P300 event-related potential brain-computer interface (BCl). Biological psychology. 2006;73(3):242-252. PMID: 16860920. Available from: https://doi.org/10.1016/j. biopsycho.2006.04.007.

15. Bishop CM. Pattern Recognition and Machine Learning. New York: Springer. 2006;

16. Farwell LA, et al. Talking off the top of your head: toward a mental prosthesis utilizing event-related brain potentials. Electroencephalography and clinical Neurophysiology. 1988;70(6):510-523. Available from: https://doi.org/10.1016/ 0013-4694(88)90149-6. 